\title{
Temporary loss of consciousness during cetuximab treatment of a patient with metastatic colon cancer: a case report
}

Taro Fukui, Koichi Suzuki* ${ }^{*}$, Sawako Tamaki, Iku Abe, Yuhei Endo, Hideki Ishikawa, Nao Kakizawa, Fumiaki Watanabe, Masaaki Saito, Shingo Tsujinaka, Kazushige Futsuhara, Yasuyuki Miyakura, Hiroshi Noda and Toshiki Rikiyama

\begin{abstract}
Background: Anti-epidermal growth factor receptor (EGFR) antibody is widely used for the treatment of patients with metastatic colorectal cancer. Hypomagnesemia is a comparatively frequent adverse event of this drug, which is likely overlooked because it occurs later in treatment without symptoms. Furthermore, hypomagnesemia and hypomagnesemia-induced corrected QT (QTC) prolongation may lead to loss of consciousness (LOC), the onset of which is not generally considered associated with the treatment of anti-EGFR antibody because of its rare occurrence. Here, we present a colorectal cancer patient treated with anti-EGFR antibody, who suffered LOC during treatment while severe hypomagnesemia or QTc prolongation was not observed.
\end{abstract}

Case presentation: A 69-year-old man with metastatic colon cancer was treated with cetuximab (anti-EGFR antibody) plus irinotecan as third-line chemotherapy. His serum magnesium level gradually decreased, and grade 2 hypomagnesemia (a serum magnesium level of $0.9 \mathrm{mg} / \mathrm{dL}$ ) was observed at the 12th administration of cetuximab. In light of this development, intravenous supplementation of $20 \mathrm{mEq}$ magnesium sulfate began with careful blood monitoring despite the lack of clinical symptoms. Electrocardiogram (ECG) showed prolonged QT or corrected QT (QTC) intervals (grade 1). His serum magnesium level remained at $0.9 \mathrm{mg} / \mathrm{dL}$, and no hypomagnesemia symptoms were observed by the 17th administration of cetuximab. After the treatment, however, he suddenly lost consciousness without symptoms related to infusion or allergic reactions. Circulatory collapse following dermatological reactions and respiratory events were not evident. Intravenous supplementation of magnesium sulfate was administered again. He awakened 2 min after the onset of temporary LOC without any other symptoms related to hypomagnesemia, such as lethargy, tremor, tetany, and seizures. No other etiology outside of the low level of serum magnesium was confirmed in further examinations. Cetuximab was discontinued, and his serum magnesium level returned to a level within the normal range after 6 weeks. Because of tumor progression, regorafenib and TAS-102 (trifluridine tipiracil hydrochloride) were introduced sequentially for 6 months. Five months after the final treatment of TAS-102, he died of his primary disease, which reflected a survival period of 4 years and 6 months since the beginning of treatment.

Conclusions: This case report reminds clinicians that LOC can be induced without severe hypomagnesemia or QTc prolongation, during anti-EGFR antibody treatment for metastatic colorectal cancer even while under carefully monitored magnesium supplementation.

Keywords: Temporary loss of consciousness, Cetuximab, Serum magnesium, Colon cancer

\footnotetext{
* Correspondence: ksuzbnhm@yahoo.co.jp

Department of Surgery, Saitama Medical Center, Jichi Medical University,

1-847 Amanuma-cho, Omiya-ku, Saitama 330-8503, Japan
} 


\section{Background}

Combination therapy comprising anti-epidermal growth factor receptor (EGFR) antibody and anti-cytotoxic drugs has shown a survival benefit as a first-line [1], as well as a second-, third-, and salvage-line chemotherapy [2-7] for patients with metastatic colorectal cancer (mCRC) without RAS mutations. The adverse event of hypomagnesemia is comparatively frequent with anti-EGFR antibody treatment [8] but is likely to be overlooked because it occurs in later treatment periods, and hypomagnesemia is asymptomatic until it becomes severe [9]. Furthermore, hypomagnesemia and hypomagnesemia-induced QTc prolongation may lead to a loss of consciousness (LOC) [10-13], but few papers have reported the association of anti-EGFR antibody treatment with the induction of loss of consciousness (LOC) $[14,15]$. Herein, we present a mCRC patient treated with anti-EGFR antibody, who showed LOC during treatment while severe hypomagnesemia or QTc prolongation was not observed.

\section{Case presentation}

A 69-year-old man with ascending colon cancer and multiple liver metastases was treated with cetuximab plus irinotecan as third-line chemotherapy. Because of bowel obstruction symptoms such as abdominal pain and vomiting, he had undergone laparoscopically assisted right hemicolectomy with D3 lymph node dissection followed by chemotherapy. The pathological finding revealed welldifferentiated adenocarcinoma. Sequential treatments were carried out, including XELOX (capecitabine 2000 $\mathrm{mg} / \mathrm{m}^{2} /$ day p.o., twice daily for 14 consecutive days; oxaliplatin $130 \mathrm{mg} / \mathrm{m}^{2}$ on day 1) plus bevacizumab $(7.5 \mathrm{mg} / \mathrm{kg}$ on day 1) as first-line chemotherapy and XELIRI (capecitabine $2000 \mathrm{mg} / \mathrm{m}^{2} /$ day p.o., twice daily for 14 consecutive days; irinotecan $150 \mathrm{mg} / \mathrm{m}^{2}$ on day 1) as second-line chemotherapy. Cetuximab (initial dose $400 \mathrm{mg} / \mathrm{m}^{2}$, subsequent doses $250 \mathrm{mg} / \mathrm{m}^{2}$ weekly) plus irinotecan (150 mg/ $\mathrm{m}^{2}$, on days 1,15 , and 29) were introduced in 7-week cycles as third-line chemotherapy. For the premedication of cetuximab, dexamethasone sodium phosphate $(6.6 \mathrm{mg})$, dl-chlorpheniramine maleate $(5 \mathrm{mg})$, and famotidine (20 $\mathrm{mg}$ ) were administered for about $30 \mathrm{~min}$, accompanied by magnesium sulfate $(40 \mathrm{mEq})$. The adverse events associated with the skin were well controlled, and Common Terminology Criteria for Adverse Events (CTCAE) version 4 grades 1-2 [16] were managed by prophylaxis with oral intake of minocycline and steroidal external agents. The patient's serum magnesium level was checked each time to prevent hypomagnesemia induced by the cetuximab treatment. At first, no oral prophylactic supplementation of oxidative magnesium was needed. At the sixth administration of cetuximab, his serum magnesium level decreased to $1.6 \mathrm{mg} / \mathrm{dL}$ (grade 1 hypomagnesemia). At the 12th administration of cetuximab, his serum magnesium level decreased to $0.9 \mathrm{mg} / \mathrm{dL}$ (grade 2 hypomagnesemia). Intravenous supplementation of $20 \mathrm{mEq}$ magnesium sulfate was administered at each treatment despite the lack of clinical symptoms. The dose of cetuximab plus irinotecan was reduced to the second level due to bone marrow suppression. The serum magnesium level remained at 0.9 $\mathrm{mg} / \mathrm{dL}$, and an ECG showed grade 1 prolonged QT or QTc intervals (Table 1). His serum magnesium level remained at $0.9 \mathrm{mg} / \mathrm{dL}$, and no hypomagnesemia symptoms were observed by the 17th administration of cetuximab. After the treatment, however, he suddenly lost consciousness and fell down to the floor when he stood up to leave the bed. He did not respond to a verbal stimulus. He was pale with cold limbs and without a radial pulse, but no symptoms related to infusion or allergic reactions were observed. Circulatory collapse following dermatological reactions and respiratory events, such as airway obstruction and edema, were not evident. Intravenous supplementation of magnesium sulfate was administered again. He awakened $2 \mathrm{~min}$ after the onset of temporary LOC without any other symptoms related to hypomagnesemia, such as lethargy, tremor, tetany, and seizures. His vital signs were as follows: blood pressure $128 / 74 \mathrm{mmHg}$ and pulse 52 beats/minute. No hemorrhage or infarction was observed in a computed tomography (CT) scan. Electrocardiogram (ECG) showed a complete right bundle branch block with sinus rhythm. The grade 1 QT and QTc intervals did not significantly change before and after the onset of LOC (Table 2). Laboratory data showed hypermagnesemia $(2.8 \mathrm{mg} / \mathrm{dL})$ due to the

Table 1 Time course of serum magnesium level, ECG, level of dose reduction of chemotherapy, and supplementation of magnesium

\begin{tabular}{|c|c|c|c|c|c|}
\hline Total number of administrations & Mg sulfate supplementation & Dose reduction & Abnormality on ECG & Serum Mg & CTCAE grade \\
\hline 12 & $20 \mathrm{mEq}$ & None & No & $0.9 \mathrm{mg} / \mathrm{dL}$ & 2 \\
\hline 13 & $20 \mathrm{mEq}$ & 1st level & No & $1.0 \mathrm{mg} / \mathrm{dL}$ & 2 \\
\hline 14 & $20 \mathrm{mEq}$ & 1st level & No & $0.9 \mathrm{mg} / \mathrm{dL}$ & 2 \\
\hline 15 & $40 \mathrm{mEq}$ & 2nd level & No & $0.9 \mathrm{mg} / \mathrm{dL}$ & 2 \\
\hline 16 & $40 \mathrm{mEq}$ & 2nd level & No & $0.9 \mathrm{mg} / \mathrm{dL}$ & 2 \\
\hline 17 & $40 \mathrm{mEq}$ & 2nd level & No & $0.9 \mathrm{mg} / \mathrm{dL}$ & 2 \\
\hline
\end{tabular}

Mg magnesium, irinotecan, ECG electrocardiogram, CTCAE Common Terminology Criteria for Adverse Events 
Table 2 QT and QTc intervals on electrocardiogram before and after onset of loss of consciousness (LOC)

\begin{tabular}{lll}
\hline Occasion & QT (msec) & QTc (msec) \\
\hline At the colectomy (4 years before LOC) & 460 & 435 \\
One week before LOC & 458 & 445 \\
Before drip infusion & 462 & 455 \\
Just after LOC & 502 & 472 \\
After admission & 500 & 478 \\
The next day after LOC & 458 & 458 \\
\hline
\end{tabular}

prophylactic administration of magnesium sulfate after drip infusion of cetuximab (Table 3). Cardiac ultrasonography displayed normal left ventricular contraction without vulvar disease, visual ejection fraction over $50 \%$, no mitral valve relapse, no atrial valve relapse, no focal asynergy, no D-shaped left ventricle, $16 \mathrm{~mm}$ of fair collapse in the inferior vena cava (IVC), and an 11.6 transtricuspid pressure gradient. He was admitted for observation and further examination. One day after the onset of LOC, his serum magnesium level was $1.5 \mathrm{mg} / \mathrm{dL}$ and his clinical

Table 3 Laboratory data before administration of cetuximab and just after loss of consciousness

\begin{tabular}{|c|c|c|}
\hline & Before administration & Just after LOC \\
\hline WBC $(/ \mu \mathrm{L})$ & 4410 & 3400 \\
\hline $\mathrm{RBC}\left(\times 10^{4} / \mu \mathrm{L}\right)$ & 299 & 276 \\
\hline $\mathrm{Hgb}(\mathrm{g} / \mathrm{dL})$ & 9.6 & 8.6 \\
\hline $\operatorname{PLT}\left(\times 10^{4} / \mu \mathrm{L}\right)$ & 16.8 & 15.3 \\
\hline $\mathrm{TP}(\mathrm{g} / \mathrm{dL})$ & 5.3 & \\
\hline Alb (g/dL) & 3.2 & \\
\hline T-Bil (mg/dL) & 0.33 & \\
\hline AST (mU/mL) & 31 & 27 \\
\hline $\mathrm{ALT}(\mathrm{mU} / \mathrm{mL})$ & 29 & 26 \\
\hline LDH (mU/mL) & 252 & 229 \\
\hline ALP (mU/mL) & 266 & 250 \\
\hline CRP (mg/dL) & 0.16 & 0.13 \\
\hline $\mathrm{Na}(\mathrm{mmol} / \mathrm{L})$ & 143 & 141 \\
\hline $\mathrm{K}(\mathrm{mmol} / \mathrm{L})$ & 4.2 & 3.8 \\
\hline $\mathrm{Cl}(\mathrm{mmol} / \mathrm{L})$ & 111 & 113 \\
\hline Ca (mg/dL) & 8.0 & 7.2 \\
\hline $\mathrm{IP}(\mathrm{mg} / \mathrm{dL})$ & 2.7 & 2.5 \\
\hline $\mathrm{Mg}(\mathrm{mg} / \mathrm{dL})$ & 0.9 & 2.8 \\
\hline BUN (mg/dL) & 11 & 10.0 \\
\hline $\mathrm{Cr}(\mathrm{mg} / \mathrm{dL})$ & 1.00 & 0.81 \\
\hline $\mathrm{eGFR}\left(\mathrm{mL} / \mathrm{min} / 1.73 \mathrm{~m}^{2}\right)$ & 56.6 & 71.3 \\
\hline
\end{tabular}

WBC white blood cell, $R B C$ red blood cell, $H g b$ hemoglobin, PLT platelet, TP total protein, Alb albumin, T-Bil total bilirubin, AST aspartate aminotransferase, $A L T$ alanine aminotransferase, $L D H$ lactate dehydrogenase, $A L P$ alkaline phosphatase, CRP C-reactive protein, $\mathrm{Na}$ sodium, $K$ potassium, $\mathrm{Cl}$ chloride, $\mathrm{Ca}$ calcium, $P$ phosphorus, $M g$ magnesium, $B U N$ blood urea nitrogen, $\mathrm{Cr}$ creatinine, eGFR estimated glomerular filtration rate symptoms had completely disappeared. The patient was then discharged. No significant arrhythmia was detected by Holter ECG; thus, paroxysmal arrhythmia was excluded as an associated reason for the LOC. His serum magnesium level was checked regularly, and intravenous supplementation ( $40 \mathrm{mEq}$ magnesium sulfate) was administered twice weekly for 2 weeks and once weekly for 5 weeks (nine times total) in the outpatient unit. Afterwards, administration of cetuximab was discontinued. The serum magnesium level returned to a normal range $(1.7-2.5 \mathrm{mg} /$ dL) after approximately 6 weeks. Follow-up CT scans detected enlarged metastatic lymph nodes in the left supraclavicular and para-aortic region and newly emerging lumbar vertebral metastasis, showing progressive disease. Regorafenib and TAS-102 (trifluridine tipiracil hydrochloride) were introduced sequentially for 6 months. Five months after the final treatment of TAS-102, he died of his primary disease, which reflected a survival period of 4 years and 6 months since the beginning of treatment.

\section{Discussion}

This report presented a case of a patient who lost consciousness just after treatment with anti-EGFR antibody despite management of hypomagnesemia $(0.9 \mathrm{mg} / \mathrm{dL})$. Magnesium deficiency may cause LOC in connection with nervous or muscular disorder, but no direct evidence was observed in this case. Arrhythmia may lead to LOC by affecting the cardiovascular or nervous systems. Cardiac ultrasonography, Holter ECG, and brain CT findings showed no abnormalities, except slightly prolonged QTc intervals in the ECG before treatment. This case report serves as a reminder to clinicians that LOC can be induced without severe hypomagnesemia or QTc prolongation during anti-EGFR antibody treatment.

It is rarely reported that treatment with anti-EGFR antibody can cause LOC. Out of 4603 cases $(11,069$ administrations) from September 19, 2008, to October 2, 2011, only 3 cases were recorded in the reports of adverse events in safety information in Japan [14, 15]. Among these three patients, the first lost consciousness accompanied by allergic symptoms 5 min after the administration of cetuximab; therefore, this was likely an infusion reaction. The second patient showed LOC 1 day after the administration of cetuximab. The report on the third patient did not include detailed information about the period of onset of LOC (Table 4). Adverse events such as syncope and LOC have been reported as symptoms induced by infusion reaction. Most infusion-related reactions happen early in the infusion or within $1 \mathrm{~h}$ of the end of the infusion, during administration of the initial cetuximab treatment. Considering the onset of LOC after complete infusion of cetuximab at the 17th treatment, it is unlikely that an infusion reaction is implicated in the onset of LOC in this patient. However, 
Table 4 Details of cases of loss of consciousness on the manufacturer's reports of adverse events

\begin{tabular}{|c|c|c|c|c|c|c|c|}
\hline Sex & Age & $\begin{array}{l}\text { Relationship } \\
\text { with Cet }\end{array}$ & Outcome & $\begin{array}{l}\text { Period from the } \\
\text { infusion }\end{array}$ & $\begin{array}{l}\text { Diagnosis } \\
\text { (metastatic site) }\end{array}$ & Concomitant drug & $\begin{array}{l}\text { Under } \\
\text { investigation }\end{array}$ \\
\hline Female & 60 & Yes & Recovered & $5 \mathrm{~min}$ & $\begin{array}{l}\text { Colon cancer } \\
\text { (peritoneum, lymph nodes) }\end{array}$ & Dexamethasone, Azasetron & \\
\hline Male & 80 & Yes & Recovered & 1 day & Colon cancer (liver) & Chlorpheniramine, Dexamethasone, Granisetron & \\
\hline Male & 70 & Yes & $\begin{array}{l}\text { Not } \\
\text { recovered }\end{array}$ & Not mentioned & Colon cancer & Fluorouracil, calcium folinate, oxaliplatin & Yes \\
\hline
\end{tabular}

Cet cetuximab, DEX dexamethasone sodium phosphate, Azasetron azasetron hydrochloride, Chlorpheniramine chlorpheniramine maleate, Granisetron granisetron hydrochloride

several patients have shown severe infusion reactions after several cetuximab treatments [17]. No symptoms related to infusion reaction or allergic reaction were recognized outside of LOC. These reactions usually begin with circulatory collapse following dermatological reactions and respiratory events, such as airway obstruction and edema, all of which were not evident in this patient. Changes in vital signs, such as blood pressure and pulse, were also frequently observed during these reactions; however, vital signs of the patient were stable during LOC. All things considered, it is unlikely that infusion or allergic reactions were involved in the onset of LOC in this patient.

Hypomagnesemia is likely induced by several drugs including anti-EGFR antibodies (Table 5) [18]. Grade 2 hypomagnesemia in this patient may have been involved in LOC despite the lack of evidence. Magnesium plays a variety of physiological and biochemical roles in the body. Symptoms of magnesium deficiency may affect nerves, muscles, mental status, and circulatory or digestive organs. In cases of nervous or muscular disorder, neurologic hypersensitivity symptoms develop, including tremor, myoclonus, muscle weakness, ataxia, tetany, muscle cramps, dizziness, nystagmus, convulsions, or coma. Among these symptoms, general fatigue is often found in hypomagnesemia and is a common clinical manifestation even in cancer patients without hypomagnesemia. Therefore, it is difficult to predict hypomagnesemia from clinical symptoms. The specific mechanism of hypomagnesemia induced by anti-EGFR antibodies is not well known. The EGFR pathway is inhibited by antiEGFR antibodies, which leads to an inhibition of magnesium reabsorption by transient receptor potential cation

Table 5 Drugs associated with hypomagnesemia

Diuretics (furosemide, thiazide)

Epidermal growth factor receptor inhibitors (cetuximab)

Proton pump inhibitors (all, such as omeprazole)

Platinum derivatives (cisplatin, carboplatin)

Calcineurin inhibitors (cyclosporin A, tacrolimus)

Antimicrobials (aminoglycosides, pentimidine, rapamycin, amphotericin B, foscarnet) channel, subfamily $M$, member 6 (TRPM6) in the renal tubules, accompanying hypomagnesemia [8, 19]. In addition, malabsorption of magnesium in the intestinal tract [8] and tubular impairment by the precipitation of the monoclonal antibody [20] are involved in this mechanism. The incidence of hypomagnesemia in cetuximab plus irinotecan treatment was $33.8 \%$ for any grade and $8.4 \%$ for grades 3/4 [21]. However, few cases develop grade 4 hypomagnesemia, which forces discontinuation of antibody therapy [8]. The longer patients are treated with cetuximab, the more often they experience hypomagnesemia [22]. In our patient, grade 1 hypomagnesemia occurred 1 month after the administration of cetuximab, while LOC was observed 5 months after its administration.

Acquired long QT interval is a disorder of cardiac repolarization that is most often induced by specific drugs, hypokalemia, or hypomagnesemia that may precipitate torsade de pointes and cause syncope and sudden cardiac death [10, 11]. Normal QTc values in the adult population are $350-450 \mathrm{~ms}$ and $360-460 \mathrm{~ms}$ for males and females, respectively [23]. The patient showed a slightly prolonged QTc (> $450 \mathrm{~ms}$ ) that was classified as a grade 1 adverse event. Syncope is the sudden transient loss of consciousness and is common both in the general population and in patients in acute care settings $[12,13]$. According to the Canadian Syncope Risk Score to predict serious adverse events, in 5010 patients with syncope, a QTc interval > $480 \mathrm{~ms}$ was a risk factor for the development of serious adverse events. Interestingly, among 5010 patients with syncope, the mean QTc interval in 4904 patients, who did not show serious adverse events, was $432.4 \mathrm{~ms}$, whereas in 106 patients, who developed serious adverse events, it was $467.4 \mathrm{~ms}$, suggesting a prolonged QTc interval $<480 \mathrm{~ms}$ may lead to LOC. Considering these data, a prolonged QTc interval can be involved in the onset of LOC in this patient, although it was $472 \mathrm{~ms}$ (grade 1 adverse event) just after the onset of LOC.

The serum magnesium level was monitored from the beginning of treatment, and magnesium was supplied by drip infusion of magnesium sulfate prior to the manifestation of the clinical symptoms. The level of magnesium 
between serum and cells is not balanced immediately; thus, the gross levels of magnesium in the body may be insufficient despite a normal level of magnesium in the serum. In addition, it takes time for recovery after the manifestation of serum hypomagnesemia because intracellular magnesium is depleted. The safety information for cetuximab [17] recommends periodic monitoring for hypomagnesemia during and for at least 8 weeks following the completion of cetuximab therapy. Our patient took approximately 6 weeks to show a level of magnesium within the normal range after discontinuation of cetuximab. In order to prevent a decrease in serum magnesium levels, oral intake of magnesium oxide could be useful from the beginning of cetuximab treatment [24]. Intravenous supplementation with magnesium sulfate is recommended because oral supplementation of magnesium does not provide efficient absorption [8, 22]; however, there is no consensus regarding methods to adjust serum magnesium levels.

\section{Conclusions}

We experienced a patient with LOC accompanied by mild hypomagnesemia and QTc prolongation under treatment with anti-EGFR antibody for mCRC. The LOC occurred under careful monitoring of the serum level of magnesium with supplementation and ECG. This case report reminds clinicians that LOC can be induced without severe hypomagnesemia or QTc prolongation during treatment with anti-EGFR antibodies.

\section{Abbreviations}

ECG: Electrocardiogram; EGFR: Epidermal growth factor receptor; LOC: Loss of consciousness; TAS-102: Trifluridine tipiracil hydrochloride

\section{Acknowledgements}

The present study was supported by a Grant-in-Aid for Scientific Research (grant number JP16K10514) from the Ministry of Education, Culture, Sports, Science and Technology.

\section{Authors' contributions}

TF and KS acquired the data and drafted the manuscript. KS administered the chemotherapy. All other authors attended the patient postoperatively. All authors read and approved the final manuscript.

\section{Funding}

The authors declare that they received no funding support for this study.

\section{Availability of data and materials}

Not applicable.

\section{Ethics approval and consent to participate}

The publication of the present study was undertaken in accordance with the ethical standards of our institution.

\section{Consent for publication}

Informed consent was obtained from the patient and his family for the publication of this report.

\section{Competing interests}

The authors declare that they have no competing interests.
Received: 29 May 2019 Accepted: 13 September 2019

Published online: 21 October 2019

\section{References}

1. Stintzing S, Modest DP, Rossius L, Lerch MM, von Weikersthal LF, Decker T, Kiani A, Vehling-Kaiser U, Al-Batran SE, Heintges T, et al. FOLFIRI plus cetuximab versus FOLFIRI plus bevacizumab for metastatic colorectal cancer (FIRE-3): a post-hoc analysis of tumour dynamics in the final RAS wild-type subgroup of this randomised open-label phase 3 trial. Lancet Oncol. 2016; 17:1426-34.

2. Amado RG, Wolf M, Peeters M, Van Cutsem E, Siena S, Freeman DJ, Juan T, Sikorski R, Suggs S, Radinsky R, et al. Wild-type KRAS is required for panitumumab efficacy in patients with metastatic colorectal cancer. J Clin Oncol. 2008;26:1626-34.

3. Cunningham D, Humblet $Y$, Siena $S$, Khayat D, Bleiberg H, Santoro A, Bets $D$, Mueser M, Harstrick A, Verslype C, et al. Cetuximab monotherapy and cetuximab plus irinotecan in irinotecan-refractory metastatic colorectal cancer. N Engl J Med. 2004;351:337-45.

4. Hecht JR, Cohn A, Dakhil S, Saleh M, Piperdi B, Cline-Burkhardt M, Tian Y, Go WY. SPIRITT: a randomized, multicenter, phase II study of panitumumab with FOLFIRI and bevacizumab with FOLFIRI as second-line treatment in patients with unresectable wild type KRAS metastatic colorectal cancer. Clin Colorectal Cancer. 2015;14:72-80.

5. Jonker DJ, O'Callaghan CJ, Karapetis CS, Zalcberg JR, Tu D, Au HJ, Berry SR, Krahn M, Price T, Simes RJ, et al. Cetuximab for the treatment of colorectal cancer. N Engl J Med. 2007:357:2040-8.

6. Karapetis CS, Khambata-Ford S, Jonker DJ, O'Callaghan CJ, Tu D, Tebbutt NC Simes RJ, Chalchal H, Shapiro JD, Robitaille S, et al. K-ras mutations and benefit from cetuximab in advanced colorectal cancer. N Engl J Med. 2008; 359:1757-65.

7. Van Cutsem E, Peeters M, Siena S, Humblet Y, Hendlisz A, Neyns B, Canon $J$, Van Laethem JL, Maurel J, Richardson G, et al. Open-label phase III trial of panitumumab plus best supportive care compared with best supportive care alone in patients with chemotherapy-refractory metastatic colorectal cancer. J Clin Oncol. 2007;25:1658-64.

8. Tejpar S, Piessevaux H, Claes K, Piront P, Hoenderop JG, Verslype C, Van Cutsem E. Magnesium wasting associated with epidermal-growth-factor receptor-targeting antibodies in colorectal cancer: a prospective study. Lancet Oncol. 2007:8:387-94.

9. Drug information of cetuximab. http://uspl.lilly.com/erbitux/erbitux.html Accessed 16 Jan 2019.

10. Kallergis EM, Goudis CA, Simantirakis EN, Kochiadakis GE, Vardas PE. Mechanisms, risk factors, and management of acquired long QT syndrome: a comprehensive review. ScientificWorldJournal. 2012;2012: 212178.

11. Kapoor WN. Syncope. In: Walker HK, Hall WD, Hurst JW, editors. Clinical methods: the history, physical, and laboratory examinations. 3rd. Boston; 1990.

12. Thiruganasambandamoorthy V, Kwong K, Wells GA, Sivilotti MLA, Mukarram M, Rowe BH, Lang E, Perry JJ, Sheldon R, Stiell IG, et al. Development of the Canadian Syncope Risk Score to predict serious adverse events after emergency department assessment of syncope. CMAJ. 2016;188:E289-98.

13. Thiruganasambandamoorthy V, Stiell IG, Sivilotti MLA, Rowe BH, Mukarram M, Arcot K, Kwong K, McRae AD, Wells GA, Taljaard M. Predicting short-term risk of arrhythmia among patients with syncope: the Canadian Syncope Arrhythmia Risk Score. Acad Emerg Med. 2017;24:1315-26.

14. The reports of adverse events in safety information in Japan. http://www. erbitux.jp/jp.country.erbitux/ja/images/A_fukusayou_11SEP443_12041.pdf. Accessed 16 Jan 2019.

15. The reports of severe adverse events in safety information in Japan. http:// www.erbitux.jp/jp.country.erbitux/ja/images/B_juutoku_11SEP443_10612.pdf. Accessed 16 Jan 2019.

16. Common Terminology Criteria for Adverse Events (CTCAE). https://ctep. cancer.gov/protocoldevelopment/electronic_applications/ctc.htm. Accessed 16 Jan 2019.

17. The information for efficacy and safety of cetuximab. https://www.erbitux. com/hcp/efficacy-safety/crystal-mcrc.html. Accessed 16 Jan 2019.

18. Viering D, de Baaij JHF, Walsh SB, Kleta R, Bockenhauer D. Genetic causes of hypomagnesemia, a clinical overview. Pediatr Nephrol. 2017;32:1123-35.

19. Vickers MM, Karapetis CS, Tu D, O'Callaghan CJ, Price TJ, Tebbutt NC, Van Hazel G, Shapiro JD, Pavlakis N, Gibbs P, et al. Association of 
hypomagnesemia with inferior survival in a phase III, randomized study of cetuximab plus best supportive care versus best supportive care alone: NCIC CTG/AGITG CO.17. Ann Oncol. 2013;24:953-60.

20. Fakih M. Anti-EGFR monoclonal antibody-induced hypomagnesaemia. Lancet Oncol. 2007:8(5):366-7.

21. Sobrero AF, Maurel J, Fehrenbacher L, Scheithauer W, Abubakr YA, Lutz MP, Vega-Villegas ME, Eng C, Steinhauer EU, Prausova J, et al. EPIC: phase III trial of cetuximab plus irinotecan after fluoropyrimidine and oxaliplatin failure in patients with metastatic colorectal cancer. J Clin Oncol. 2008;26:2311-9.

22. Fakih MG, Wilding G, Lombardo J. Cetuximab-induced hypomagnesemia in patients with colorectal cancer. Clin Colorectal Cancer. 2006;6:152-6.

23. Viskin S. The QT interval: too long, too short or just right. Heart Rhythm. 2009;6:711-5.

24. Demizu M, Ueda H, Osawa M, Chihara S, Igarashi T, Yano K, Kimura F, Tanaka N, Hiratsuka M. Effect of magnesium supplementation on early-stage hypomagnesemia in patients treated with cetuximab. Gan To Kagaku Ryoho. 2013:40:897-900.

\section{Publisher's Note}

Springer Nature remains neutral with regard to jurisdictional claims in published maps and institutional affiliations.

\section{Submit your manuscript to a SpringerOpen ${ }^{\circ}$ journal and benefit from:}

- Convenient online submission

- Rigorous peer review

- Open access: articles freely available online

High visibility within the field

- Retaining the copyright to your article

Submit your next manuscript at $\boldsymbol{\nabla}$ springeropen.com 